\title{
Studying the effect of chloroquine on sporozoite-induced protection and immune responses in Plasmodium berghei malaria
}

Else M Bijker ${ }^{1 \dagger}$, Krystelle Nganou-Makamdop ${ }^{1,3+}$, Geert-Jan van Gemert ${ }^{1}$, Fidel Zavala ${ }^{2}$, Ian Cockburn ${ }^{2,4}$ and Robert W Sauerwein ${ }^{1 *}$

\begin{abstract}
Background: Sporozoite immunization of animals and humans under a chemo-prophylactic cover of chloroquine (CPS-CQ) efficiently induces sterile protection against malaria. In humans, CPS-CQ is strikingly more efficient than immunization with radiation attenuated sporozoites (RAS), raising the hypothesis that this might be partially due to CQ. Chloroquine, an established anti-malarial drug, is also well known for its immune modulating properties including improvement of cross-presentation. The aim of this study was to investigate whether co-administration of CQ during sporozoite immunization improves cellular responses and protective efficacy in Plasmodium berghei models.

Methods: A number of experiments in selected complimentary $P$. berghei murine models in Balb/cByJ and C57BL/6j mice was performed. First, the effect of $C Q$ administration on the induction of protection and immune responses by RAS immunization was studied. Next, the effect of CQ on the induction of circumsporozoite (CS) protein-specific CD8 ${ }^{+} \mathrm{T}$ cells by immunization with $P$. berghei parasites expressing a mutant CS protein was investigated. Finally, a direct comparison of CPS-CQ to CPS with mefloquine (MQ), an anti-malarial with little known immune modulating effects, was performed.

Results: When CQ was co-administered during immunization with graded numbers of RAS, this did not lead to an increase in frequencies of total memory $C D 8^{+} T$ cells or CS protein-specific CD8 ${ }^{+} T$ cells. Also parasite-specific cytokine production and protection remained unaltered. Replacement of CQ by MQ for CPS immunization resulted in significantly reduced percentages of IFNy producing memory T cells in the liver $(p=0.01)$, but similar protection.

Conclusions: This study does not provide evidence for a direct beneficial effect of CQ on the induction of sporozoite-induced immune responses and protection in P. berghei malaria models. Alternatively, the higher efficiency of CPS compared to RAS might be explained by an indirect effect of CQ through limiting blood-stage exposure after immunization or to increased antigen exposure and, therefore, improved breadth of the immune response.
\end{abstract}

Keywords: Chloroquine, Sporozoite immunization, P. berghei, T cells, Immunity, Protection

\section{Background}

Whole sporozoite immunization approaches, such as chloroquine chemoprophylaxis and sporozoites (CPSCQ) and radiation-attenuated sporozoites (RAS), efficiently induce protection in murine malaria models [1-3]. In humans CPS-CQ is about 20 times more

\footnotetext{
* Correspondence: robert.sauerwein@radboudumc.nl

${ }^{\dagger}$ Equal contributors

'Department of Medical Microbiology, Radboud University Medical Center, P.O. Box 9101,6500 HB Nijmegen, The Netherlands

Full list of author information is available at the end of the article
}

efficient than RAS, requiring bites from a total of 45 versus 1,000 mosquitoes, respectively [4-6]. Moreover, longlasting immune responses after CPS-CQ immunization in studies with mice [7] and healthy human volunteers [8] go together with protracted protection. Several murine studies have demonstrated the essential role of $\mathrm{CD} 8^{+} \mathrm{T}$ cells in sporozoite-induced pre-erythrocytic immunity [9-14,2]. Generation of these $\mathrm{CD} 8^{+} \mathrm{T}$ cells against pre-erythrocytic antigens requires cross-priming by dendritic cells [15].

CQ has since its discovery in 1934 been used widely and successfully as anti-malarial, until resistance developed [16],

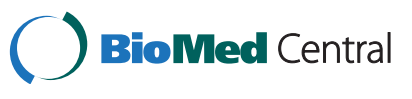

(c) 2015 Bijker et al.; licensee BioMed Central. This is an Open Access article distributed under the terms of the Creative Commons Attribution License (http://creativecommons.org/licenses/by/4.0), which permits unrestricted use, distribution, and reproduction in any medium, provided the original work is properly credited. The Creative Commons Public Domain Dedication waiver (http://creativecommons.org/publicdomain/zero/1.0/) applies to the data made available in this article, unless otherwise stated. 
and has more recently been explored for treating cancer and viral infections $[17,18]$. Interestingly, $C Q$ was also shown to enhance cross-presentation of soluble antigens and non-replicating influenza virus in vitro $[19,20]$. Moreover, in vivo cross-priming of naïve $\mathrm{CD}^{+} \mathrm{T}$ cells with soluble ovalbumin was more effective in CQ-treated compared to untreated mice [21], and CQ improved the induction of influenza-specific cytolytic T cells in mice [20]. In humans, co-administration of $C Q$ with a hepatitis $B$ vaccine booster significantly increased the number of virus-specific IFN $\gamma$-producing $\mathrm{CD}^{+} \mathrm{T}$ cells [19].

This study was based on the hypothesis that CQ, which affects endosomal acidification and the degradation and transport of antigens to the cytosol [22,23], could favour cross-presentation of pre-erythrocytic Plasmodium antigens and thereby contribute to the efficient induction of immune responses and protection by CPS-CQ immunization. The first topic of investigation was the effect of CQ on immunization by RAS, an established immunization model relying on $\mathrm{CD}^{+} \mathrm{T}$ cell responses, thus potentially benefiting from improved cross-presentation. $\mathrm{CD}^{+} \mathrm{T}$ cells recognizing the immunodominant circumsporozoite (CS) protein can mediate protective immunity [24]. Therefore, the effect of CQ on the induction of CS-specific CD8 ${ }^{+} \mathrm{T}$ cells by immunization with $P$. berghei parasites that express a mutant CS protein containing the model SIINFEKL $\mathrm{H}-2 \mathrm{~K}^{\mathrm{b}}$ epitope was investigated next. Finally, a direct comparison was performed betweeen CPS-CQ and CPS with mefloquine (MQ), an anti-malarial with little known immune modulating effects [25-27], not including improvement of cross-presentation. Akin to CQ, MQ induces arrest of early blood-stage parasites without an effect on pre-erythrocytic parasite stages, allowing full liver-stage development and brief exposure to early blood stages. By performing experiments in these selected complimentary P. berghei murine models, the aim of this study was to explore the effect of $\mathrm{CQ}$ on protection and $\mathrm{T}$ cell responses after whole sporozoite immunization.

\section{Methods}

\section{Mice and parasites}

Balb/cByJ and C57BL/6j mice (6 to 8 weeks old) were purchased from Elevage-Janvier (Le Genest Saint Isle, France). These mouse strains were selected based on extensive experience with these strains for malaria immunization studies [28]. The following parasites were used: $P$. berghei (ANKA strain) wild type parasites and $P$. berghei CS5M parasites in which the endogenous CS gene had been replaced with a modified circumsporozoite gene expressing the $\mathrm{H}-2 \mathrm{~Kb}$ restricted SIINFEKL [15]. Sporozoites were obtained by dissection of the salivary glands of infected female Anopheles stephensi mosquitoes 21-29 days after a blood meal on infected mice.
All animal studies and procedures performed in the Netherlands were approved by the Ethical Committee on Animal Research of the Radboud University Nijmegen (RU-DEC 2009-179, 2009-225, 2010-115, 2010-135). Mice were housed at the Central Animal Facility in Nijmegen and received a standard diet and water ad libitum. All animal procedures in the United States of America were approved by the Institutional Animal Care and Use Committee of the Johns Hopkins University (Protocol Number MO10H167) and followed the National Institutes of Health guidelines for animal housing and care.

\section{Immunization schedules, sporozoite challenge and assessment of protection}

Mice were immunized with one (Balb/cBy); Additional file 1A) or two to three (C57BL/6j; Additional file 1B) intravenous (iv) injections of $P$. berghei RAS (16krad, Gammacel $1000{ }^{137} \mathrm{Cs}$ ) at weekly intervals or with one intradermal injection of $P$. berghei $\mathrm{CS}^{5 \mathrm{M}}$ RAS (Additional file 1: Figure S1C). Dose de-escalation of RAS immunization was performed in order to obtain a suboptimal RAS dose to detect possible beneficial effects of CQ (Additional files 1A and 1B). In RAS experiments, RAS-CQ groups received either CQ prophylaxis (chloroquine diphosphate, Sigma-Aldrich) for 10 days (Balb/cByJ $-1040 \mu \mathrm{g}$ base/day oral) or 17 days (C57BL/6j $800 \mu \mathrm{g}$ base/day intraperitoneal). Efficacy of these prophylactic regimens was established in pilot studies, and they were chosen because of their closest resemblance to the human CPS-protocol. Alternatively, mice were given two subcutaneous injections of $500 \mu \mathrm{g} C Q$ base, $2 \mathrm{~h}$ before and $6 \mathrm{~h}$ after each immunization, because this particular regimen was previously shown to improve cross-presentation (Additional file 1B) $[21,20]$.

Furthermore, mice under $\mathrm{CQ}$ or MQ prophylaxis were immunized three times at weekly intervals by intravenous administration of 20,000 wild-type PbSPZ (CPS immunization; Additional file 1D). For CPS immunization, $\mathrm{CQ}$ (diluted in PBS) and MQ (diluted in DMSO/water for injection) were given orally for 24 consecutive days at dosage $1040 \mu \mathrm{g}$ base/day (CQ) or $350 \mu \mathrm{g}$ base/day (mefloquine hydrochloride, Sigma-Aldrich) starting from the first day of PbSPZ administration.

Challenge infections were performed by intravenous injection of 10,000 or 50,000 sporozoites around four or eleven weeks after the end of CQ/MQ prophylaxis. Giemsa-stained blood smears were screened for parasitized red blood cells every other day from days 3-14 and finally on day 21 after challenge. Protection was defined as the absence of blood-stage parasites until day 21 post-challenge (Additional files $1 \mathrm{~A}, \mathrm{~B}$ and $\mathrm{C}$ ). 
Ex vivo memory phenotyping and in vitro IFN $\gamma$ responses against sporozoites and blood-stage parasites

Mice were euthanized by isoflurane inhalation after intravenous injection of 50 units heparin. Spleen and liver were collected after perfusion of the liver with $10 \mathrm{ml}$ PBS. Cell suspensions of liver and spleen were made by passage of the organs through a $70-\mu \mathrm{m}$ nylon cell strainer (BD Labware). Liver cells were re-suspended in 35\% Percoll (GE Healthcare) and centrifuged at $800 \mathrm{~g}$ for $20 \mathrm{~min}$. Liver and spleen erythrocytes were lysed using 5 min incubation on ice in a lysing solution of ammonium chloride. After erythrocyte lysis, hepatic mononuclear cells (HMC) and splenocytes were re-suspended in RPMI 1640 medium.

Five-colour staining of HMC and splenocytes was performed using monoclonal antibodies purchased from Biolegend: Pacific blue-conjugated anti CD3 (17A2), Peridinin Chlorophyll Protein (PerCP)-conjugated anti CD4 (RM4.5), Alexa fluor 700-conjugated anti CD8a (53-6.7), fluorescein isothiocyanate (FITC)-conjugated anti-CD44, allophycocyanin (APC)- or phycoerythrinCy7 (PE-Cy7)-conjugated anti-CD62L (MEL-14). Briefly, $10^{6}$ cells were re-suspended in cold assay buffer (PBS supplemented with $0.5 \%$ bovine serum albumin (SigmaAldrich)) and incubated for $30 \mathrm{~min}$ at $4^{\circ} \mathrm{C}$ with the monoclonal antibodies. Cells were fixed with Fix \& Perm medium A (Invitrogen) and collected in an assay buffer for measurement.

For the detection of parasite-specific cytokine production, HMC and splenocytes $\left(5 \times 10^{5}\right.$ cells/well) were cocultured in complete RPMI 1640 culture medium [29] in the presence of $P$. berghei cryopreserved sporozoites $\left(\mathrm{PbSPZ}-5 \times 10^{4} / \mathrm{ml}\right)$ or infected red blood cells (PbiRBC $\left.5 \times 10^{6} / \mathrm{ml}\right)$. Exposure to salivary gland preparations from uninfected mosquitoes and uninfected red blood cells (uRBC $-5 \times 10^{6} / \mathrm{ml}$ ) were used as respective negative controls. Cells were stimulated at $37^{\circ} \mathrm{C} / 5 \% \mathrm{CO} 2$ for 24 hours and Brefeldin A (Sigma-Aldrich) was added during the last four hours $(10 \mu \mathrm{g} / \mathrm{ml}$ final concentration). As positive control, PMA (100 ng/ml) and Ionomycin $(1.25 \mu \mathrm{g} / \mathrm{ml})$ (Sigma-Aldrich) were added simultaneously along with Brefeldin A. Cells were harvested after 24-hours in vitro stimulation and stained with monoclonal antibodies against CD3, CD4, CD8a and CD44 as indicated above. Fixed and permeabilized cells were stained with PE-conjugated antiIL-2 (JES6-5H4) and APC-conjugated anti-IFN $\gamma$ (XMG1.2) in Fix \& Perm medium B (Invitrogen) at $4^{\circ} \mathrm{C}$ for $30 \mathrm{~min}$. Flow cytometry was performed on a 9-color Cyan ADP (Beckman Coulter) and data analysis was performed using FlowJo software (version 9.1; Tree Star), using a gating strategy as described previously [7].

\section{Quantification of SIINFEKL specific CD8 ${ }^{+}$T cells}

Prior to intradermal immunization with 20.000 P. berghei $\mathrm{CS}^{5 \mathrm{M}} \mathrm{RAS}, \mathrm{C} 57 \mathrm{BL} / 6 \mathrm{j}$ mice received $2 * 10^{3} \mathrm{CD} 45.1+$
OT-1 cells and the RAS-CQ group received a 10-days CQ treatment $(1040 \mu \mathrm{g}$ base/day - oral). Expansion of CD $45.1^{+} \mathrm{CD}^{+}$SIINFEKL cells in liver and spleen was assessed by flow cytometry ten days after immunization as described previously [15] (Additional file 1C).

\section{Data analysis and statistics}

Difference in protection between two groups was tested with a Fisher's exact test. Overall comparisons between immunized and naïve groups were performed using the Kruskal-Wallis test. Direct comparisons between two groups (RAS versus RAS-CQ or CPS-CQ versus CPSMQ) were performed by Mann-Whitney $U$ test. For the analysis of cytokine production, background responses to salivary glands and $\mathrm{URBC}$ were subtracted from PbSPZ and PbiRBC responses, respectively, for each individual mouse. All statistical analyses were performed using PRISM software version 5.0 (Graphpad, San Diego, CA). A p-value of $\leq 0.05$ was considered statistically significant.

\section{Results}

\section{Effects of chloroquine on RAS immunization}

First, experiments were performed to investigate whether administration of a prophylactic regimen of CQ improved $\mathrm{CD}^{+}$memory $\mathrm{T}$ cell responses induced by RAS immunization in C57BL/6j mice. Ex vivo analysis showed that percentages of $\mathrm{CD}^{+} \mathrm{T}$ cells with an effector memory phenotype $\left(\mathrm{CD} 44^{+} \mathrm{CD} 2 \mathrm{~L}^{-}\right.$; Tem) in the liver were 4-5 fold higher a day before challenge $(C-1)$ in immunized compared to naïve mice $(\mathrm{p}=0.011)$. However, the percentage of $\mathrm{CD}^{+}$Tem cells was similar in RAS versus RAS-CQ mice (Figure 1A). Similar patterns were observed in the spleen with three-fold increased Tem levels at $\mathrm{C}-1(\mathrm{p}=0.007$, Figure $1 \mathrm{~B})$.

In vitro re-exposure of immune cells to PbSPZ showed high levels of IFN $\gamma$ producing memory $\mathrm{T}$ cells in both liver and spleen of RAS-immunized mice $(p=0.003$ and 0.027 , respectively), which were not increased by additional CQ administration (Figure 2A). Similar observations were made for hepatic and splenic pluripotent memory $\mathrm{T}$ cells producing both IFN $\gamma$ and IL-2, with a major contribution of $\mathrm{CD}^{+}$cells in the liver (Figure 2B). In summary, additional $C Q$ administration affected neither frequency of RAS-induced $\mathrm{CD}^{+}$Tem cells, nor sporozoite-specific cytokine production by $\mathrm{T}$ cells.

The circumsporozoite (CS) protein is an established target protein of protective immunity in mice and humans $[24,30]$, and the effect of CQ on $\mathrm{CD}^{+} \mathrm{T}$ cell responses against a SIINFEKL $\mathrm{H}-2 \mathrm{~K}^{\mathrm{b}}$ restricted epitope integrated in this protein was studied next. In line with the results above, mice immunized with RAS whilst under CQ cover showed similar percentages of hepatic 


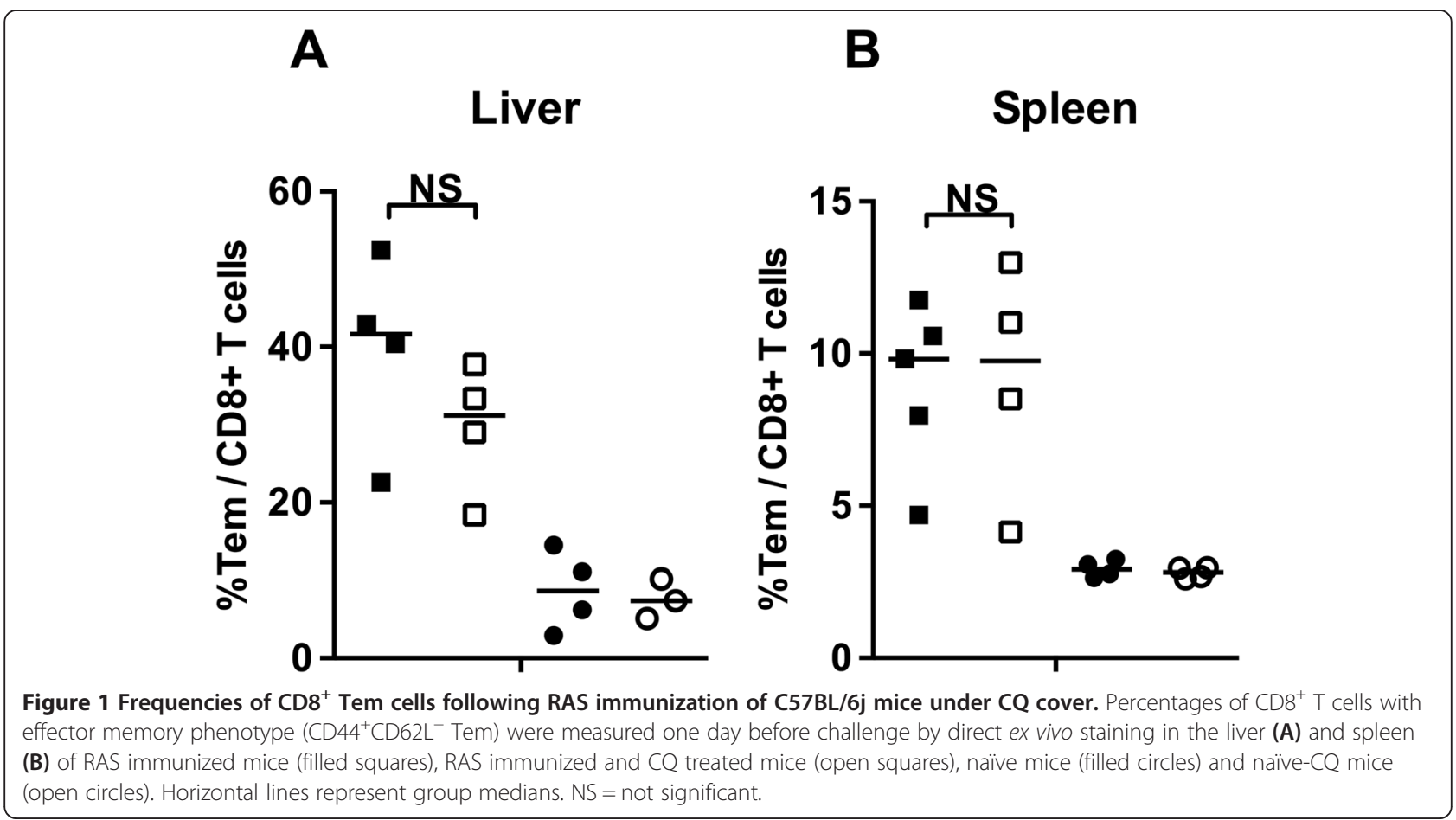

A

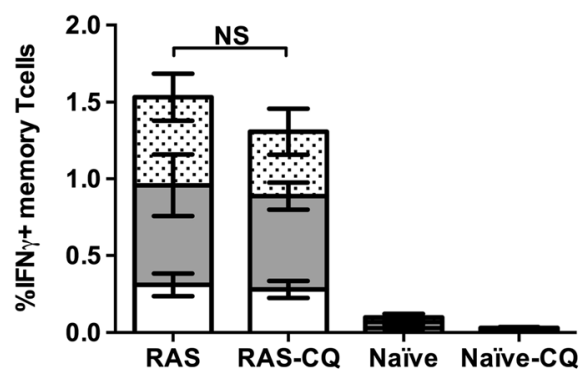

B

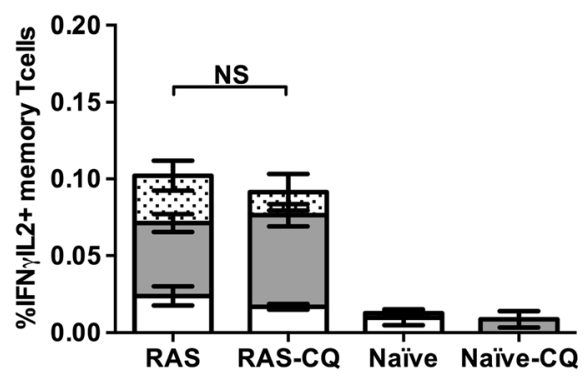

Spleen - PbSPZ

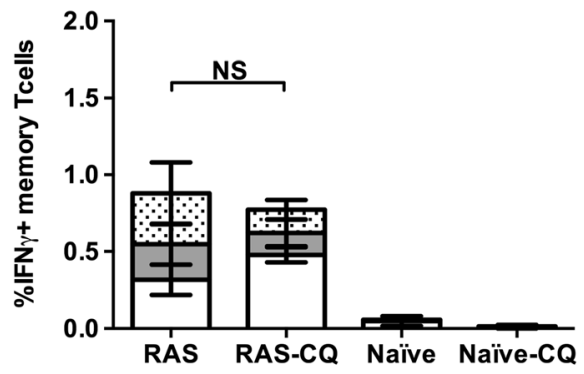

Spleen - PbSPZ

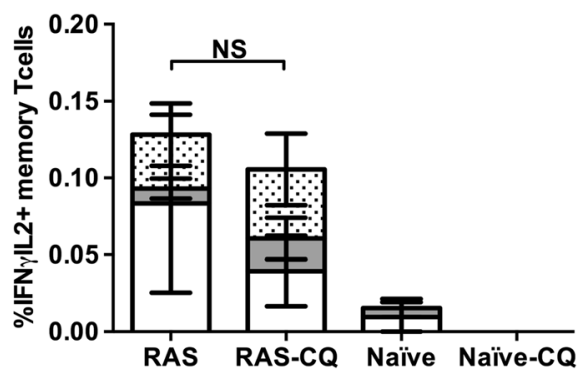

Figure 2 Sporozoite specific cytokine responses following RAS immunization under CQ cover. Percentages of IFNY (A) and IFNY and IL-2 (B) producing memory T cells were measured in RAS $(n=5)$ RAS-CQ $(n=4)$, naïve control $(n=5)$ and CQ-control $(n=4)$ mice, a day before challenge by intracellular staining after in vitro re-exposure of liver and spleen cells to $P$. berghei sporozoites (PbSPZ). Responses of CD4 ${ }^{+} T$ cells (open area), $C D 8^{+} \mathrm{T}$ cells (grey area) and $\mathrm{CD} 4^{-} \mathrm{CD} 8^{-} \mathrm{T}$ cells (dotted area) relative to total memory $\mathrm{T}$ cell responses are presented. Background responses to salivary glands were subtracted from PbSPZ responses for each individual mouse. Error bars represent standard error of the mean. NS = not significant. 
and splenic CS-specific $\mathrm{CD}^{+} \mathrm{T}$ cells compared to untreated mice (Figure 3).

To evaluate a potential effect of CQ on RAS protective efficacy, groups of Balb/cByj and C57BL/6j mice were immunized with graded numbers of RAS, then challenged and monitored for parasitemia. In both mice strains, reduction of immunization dose resulted in a stepwise decrease in protection that was not influenced by either a prophylactic regimen of daily $C Q$, or two low doses of CQ at $2 \mathrm{~h}$ before and $6 \mathrm{~h}$ after each immunization (Table 1).

The CQ administered during immunization had no effect on the challenge infection, since all control mice that received CQ-prophylaxis showed the same prepatent period as untreated naïve mice.

\section{Comparing chloroquine to mefloquine prophylaxis for CPS immunization}

Next, immune responses and protection after CPS-CQ and CPS-MQ immunization were investigated. $\mathrm{CD} 8^{+}$ Tem levels (Figure 4), IFNY production upon in vitro restimulation with $\mathrm{PbSPZ}$ or $\mathrm{PbiRBC}$ and pluripotent $\mathrm{T}$ cells producing both IFNY and IL-2 (Figure 5) were significantly increased in immunized compared to control mice.

Although not significant, there was a trend for higher $\mathrm{CD}^{+}$Tem levels in CPS-CQ compared to CPS-MQ in both liver and spleen $(p=0.08$ and 0.16 , respectively; Figure 4). T cells isolated from the liver of CPS-CQ mice showed higher IFNY responses after in vitro re-exposure to $\operatorname{PbiRBC}(\mathrm{p}=0.01)$ and a trend for higher IFNY responses to PbSPZ re-exposure $(\mathrm{p}=0.09$; Figure $5 \mathrm{~A})$. In the spleen, a similar trend of higher IFN $\gamma$ responses in the CPS-CQ group was observed upon re-exposure to PbSPZ but not PbiRBC (Figure 5B). Following in vitro re-exposure to $P b i R B C$, but not $P b S P Z$, the percentage of hepatic pluripotent memory $\mathrm{T}$ cells producing both IFN $\gamma$ and IL-2 was significantly higher in the CPS-CQ group compared to the CPS-MQ group $(p=0.02$, Figure $5 \mathrm{C})$. Thus, CPS-CQ resulted in somewhat higher specific cytokine responses compared to CPS-MQ.

Finally, mice were challenged by intravenous administration of 10,000 sporozoites five or ten weeks after the second booster (day 50 or 100) or with 50,000 sporozoites at day 50. At day 50, 100\% of CPS-CQ (13/13) and CPS-MQ (21/21) immunized mice were protected against challenge with low $(10 \mathrm{~K})$ or high $(50 \mathrm{~K})$ sporozoite dose. All control mice including CQ (10/10) and MQ (10/10) prophylaxis groups developed blood-stage parasitaemia. Postponement of challenge to day 100 resulted in $90 \%$ protection (9/10) in both the CPS-CQ and CPS-MQ group (Table 2).

Altogether, there was no difference in protection after CPS immunization with either CPS-CQ or CPS-MQ, although cellular responses after whole sporozoite immunization under CQ cover were increased.

\section{Discussion}

Addition of CQ to a $P$. berghei RAS immunization protocol improves neither protection nor parasitespecific $\mathrm{CD}^{+} \mathrm{T}$ cells responses. Only slightly reduced $\mathrm{T}$ cell responses and similar protective efficacy are found when CPS-CQ is compared to CPS-MQ. This study did not involve an investigation of the effect of $C Q$ on cross-presentation in vitro, nor detailed mechanistic antigen presentation studies [31]. Alternatively, more
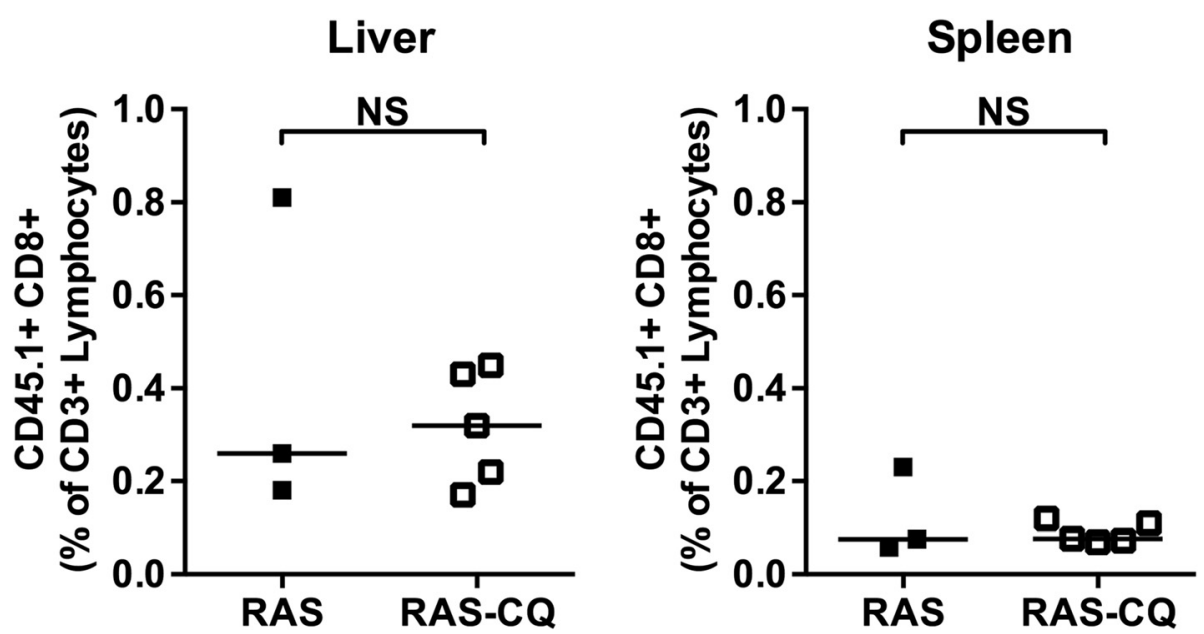

Figure 3 Frequencies SIINFEKL specific CD8 ${ }^{+}$T cells following RAS immunization under CQ cover. Prior to RAS intradermal immunization with (RAS-CQ) or without chloroquine (RAS), mice received injection of SIINFEKL-specific CD8 ${ }^{+} \mathrm{T}$ cells. Ten days after a single immunization, expansion of CD45. $1^{+} \mathrm{CD}^{+}$SIINFEKL-specific cells was determined in the liver and spleen of both immunized groups. NS= not significant. 
Table 1 Effect of chloroquine on RAS protective efficacy

\begin{tabular}{|c|c|c|c|c|c|}
\hline \multirow[b]{2}{*}{ Immunization } & \multirow[b]{2}{*}{ Mouse strain } & \multirow[b]{2}{*}{ Immunization dose (x10 ${ }^{3}$ RAS PbSPZ) } & \multirow[b]{2}{*}{ Inoculations (n) } & \multicolumn{2}{|c|}{ No. protected/ no. challenged } \\
\hline & & & & Chloroquine - & Chloroquine $+^{\#}$ \\
\hline \multirow[t]{7}{*}{ RAS } & Balb/cByJ & 1 & 1 & $14 / 16(88)$ & $13 / 16(81)$ \\
\hline & & 0.5 & 1 & $4 / 10(40)$ & $4 / 10(40)$ \\
\hline & & 0.3 & 1 & $5 / 10(50)$ & $2 / 10(20)$ \\
\hline & C57BL/6j & 10 & 3 & $5 / 5(100)$ & $4 / 5(80)$ \\
\hline & & 4 & 3 & $4 / 5(80)$ & $4 / 5(80)$ \\
\hline & & 1 & 3 & $0 / 5(0)$ & $1 / 5(20)$ \\
\hline & & 4 & 2 & $15 / 23(65)$ & $14 / 23(61)^{\# \#}$ \\
\hline \multirow[t]{2}{*}{ None } & Balb/cByJ & N/A & N/A & $1 / 6(16)$ & $0 / 6(0)$ \\
\hline & C57BL/6j & N/A & $\mathrm{N} / \mathrm{A}$ & $0 / 10(0)$ & $0 / 15(0)$ \\
\hline
\end{tabular}

\#Mice received chloroquine prophylaxis for 10 or 17 days, with the exception of the experiment indicated with \#\#, where mice received two injections of $\mathrm{CQ}, 2 \mathrm{~h}$ before and $6 \mathrm{~h}$ after each immunization.

functional readouts were examined such as parasitespecific $\mathrm{CD}^{+} \mathrm{T}$ cell responses and protection from challenge infection to assess potential immune enhancing effects of CQ. These combined P. berghei data do not provide evidence for significant improvement of whole sporozoite immunization in the presence of $\mathrm{CQ}$ and, therefore, indicate that $\mathrm{CQ}$ is not responsible for the strikingly higher efficiency of CPS-CQ compared to RAS in humans.

Improved cross-presentation resulting in increased IFN $\gamma$ production by $\mathrm{CD}^{+} \mathrm{T}$ cells has been shown in in vitro studies where dendritic cells were pulsed with soluble viral antigen in the presence of CQ [19]. In mice, CQ was shown to enhance cross-presentation of soluble OVA to OT-I cells both in vitro and in vivo and to improve specific $\mathrm{CD}^{+} \mathrm{T}$ cell responses after alum-OVA immunization [21]. An effect of CQ on OVA cross- presentation was observed upon administration of $20 \mu \mathrm{g}$, but not $200 \mu \mathrm{g}$ protein [21], suggesting that immunomodulatory effects of CQ are only beneficial under suboptimal immunization conditions. In the current study, RAS immunization both with and without CQ induces strong cellular responses with similar contribution of $\mathrm{CD}^{+} \mathrm{T}$ cells, which translates to equal protection levels. Even after down-titration of RAS immunization dose, which is associated with decreasing protection, clear improvement by CQ remains undetected.

In humans, a single administration of CQ during Hepatitis B booster vaccination significantly improved $\mathrm{CD}^{+} \mathrm{T}$ cell response [19]. Despite several reports of enhanced immune responses by $\mathrm{CQ}$ in mice and men $[21,23,32,19]$, only one study has reported improved protection; mice immunized with a heat-inactivated influenza virus showed improved survival rates after
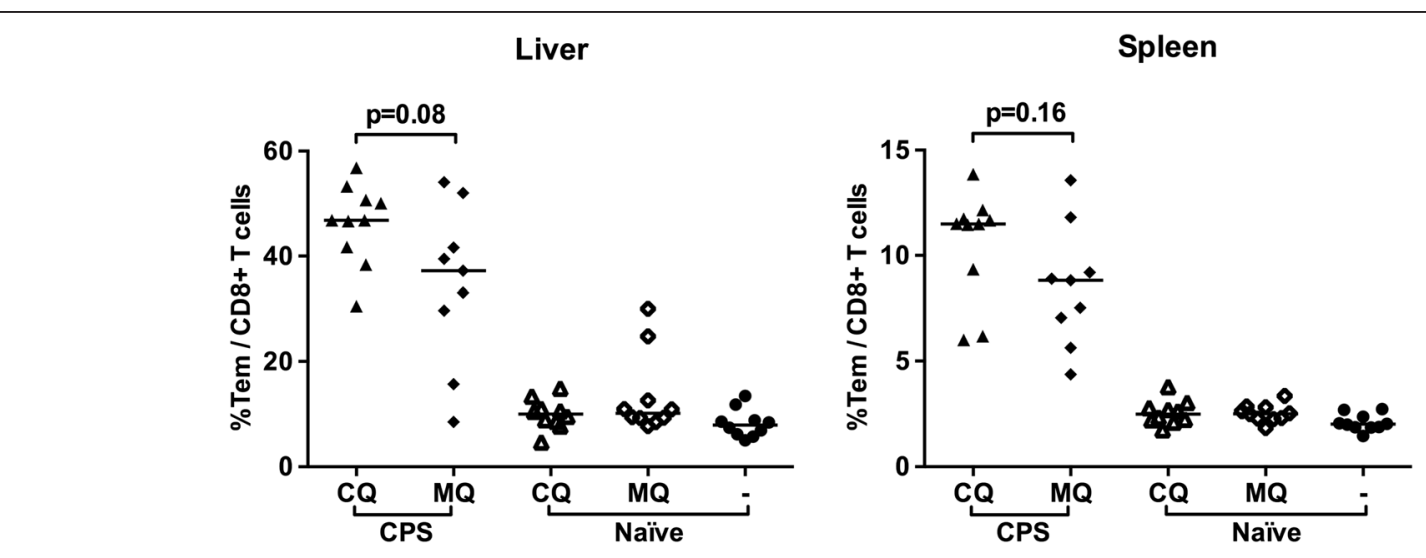

Figure 4 Frequencies of $\mathrm{CD}^{+}$Tem cells following sporozoite immunization under $\mathrm{CQ}$ or MQ cover. Percentages of $\mathrm{CD} 8^{+} \mathrm{T}$ cells with effector memory phenotype $\left(\mathrm{CD}_{4} 4^{+} \mathrm{CD} 62 \mathrm{~L}^{-} \mathrm{Tem}\right)$ were measured by direct ex vivo staining a day before challenge $(\mathrm{C}-1)$ in the liver and spleen of C57BL/6j mice immunized with sporozoites under CQ cover (filled triangle) or MQ cover (filled diamonds), naïve-CQ mice (open triangles), naïve-MQ mice (open diamonds) and untreated naïve mice (filled circles). Horizontal lines represent group medians. 


\section{A}

Liver - PbSPZ

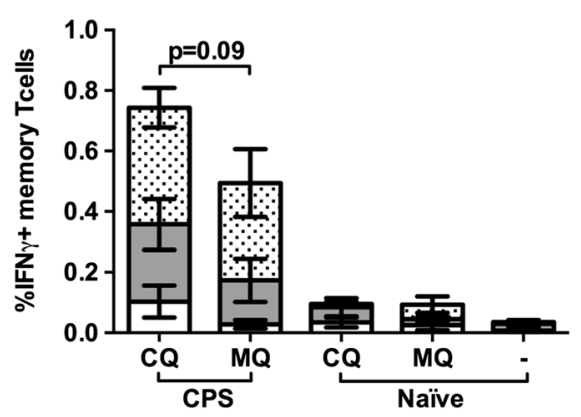

B

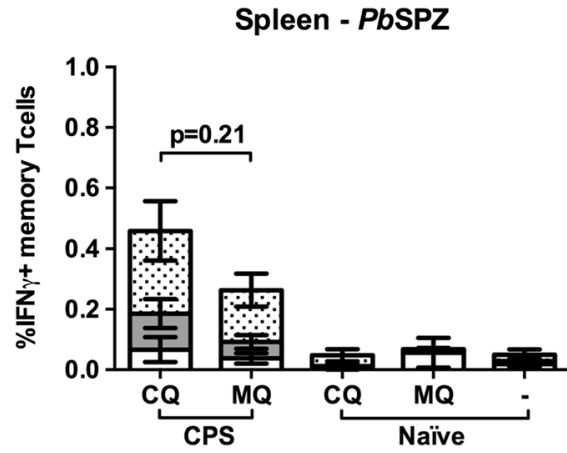

C

Liver - PbSPZ

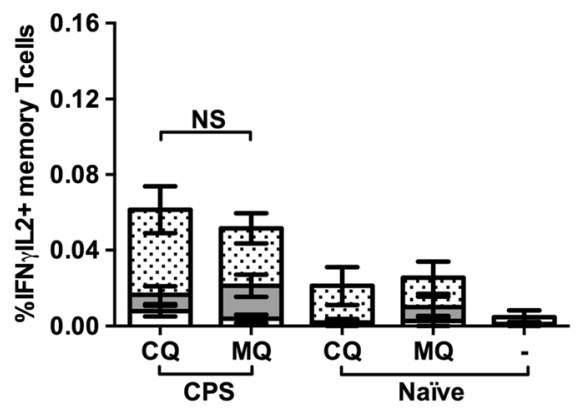

Liver - PbiRBC

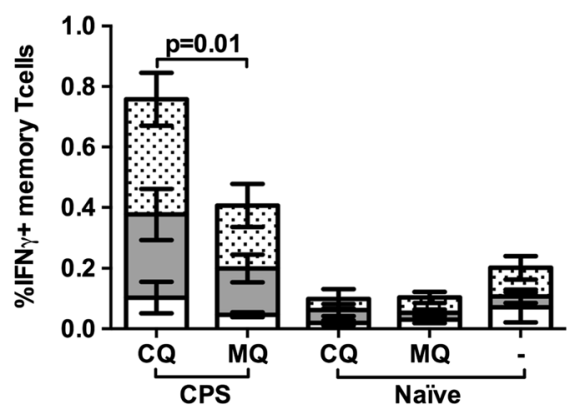

Spleen - PbiRBC

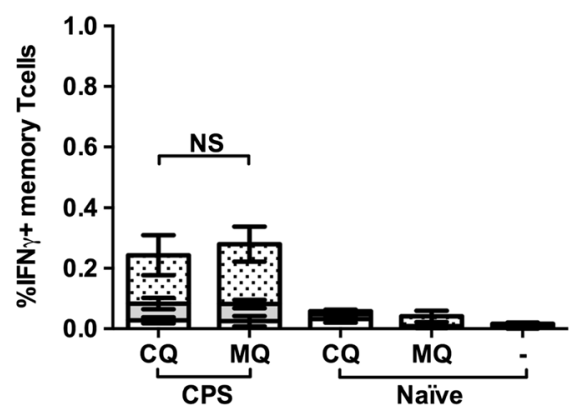

Liver - PbiRBC

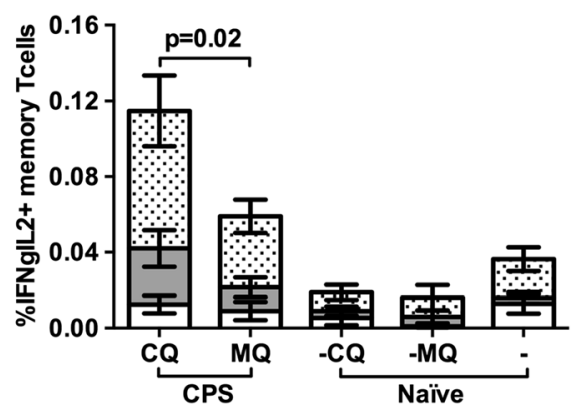

Figure 5 Sporozoite specific cytokine responses following sporozoite immunization under CQ or MQ cover. Percentages of IFNY producing memory T cells were measured in CPS-CQ $(n=10)$, CPS-MQ $(n-9)$, naïve-CQ $(n=10)$, naïve-MQ $(n=10)$ and no-drug naïve controls $(n=10)$ a day before challenge by intracellular staining after re-exposure of $(\mathbf{A})$ liver and $(\mathbf{B})$ spleen cells to $P$. berghei sporozoites (PbSPZ) or infected red blood cells (PbiRBC). Responses of $C D 4^{+} T$ cells (open area), $C D 8^{+} T$ cells (grey area) and $C D 4^{-} C D 8^{-} T$ cells (dotted area) relative to total memory $\mathrm{CD}^{+} \mathrm{T}$ cell responses are presented. (C) Hepatic IFNy and IL-2 responses of memory T cells after re-exposure to PbSPZ and PbiRBC are presented similarly. Background responses to salivary glands and uninfected red blood cells were subtracted from PbSPZ and PbiRBC responses respectively for each individual mouse. Error bars represent standard error of the mean. NS = not significant.

challenge infection [20]. The significance of improved immune responses for protection thus remains to be further explored.

One cannot assume that improvement of crosspresentation by CQ is applicable to any soluble protein or peptide, or antigens presented in the form of a whole sporozoite. Improvement of cross-presentation of SIINFEKL peptide $\left(\mathrm{OVA}_{257-264}\right)$ and inactivated influenza virus by $C Q$ in mice have been demonstrated $[21,20]$. Here however, CQ administration during sporozoite immunization with SIINFEKL expressing P. berghei sporozoites showed no increase of SIINFEKL-specific $\mathrm{CD}^{+} \mathrm{T}$ cells, suggesting that presentation pathways and effects of CQ might differ between pathogens or antigens. 
Table 2 Protection by sporozoite immunization under CQ or MQ cover

\begin{tabular}{|c|c|c|c|}
\hline & \multicolumn{3}{|c|}{ No. protected/No. challenged (\% protection) } \\
\hline & \multicolumn{2}{|c|}{ Day 50 (x10 $30^{3} \mathrm{bSPZ}$ challenge) } & \multirow{2}{*}{$\begin{array}{l}\text { Day } 100\left(\times 10^{3} \mathrm{PbSPZ} \text { challenge }\right. \\
10\end{array}$} \\
\hline & 10 & 50 & \\
\hline CPS-CQ & $3 / 3(100)$ & $10 / 10(100)$ & $9 / 10(90)$ \\
\hline CPS-MQ & $11 / 11(100)$ & $10 / 10(100)$ & $9 / 10(90)$ \\
\hline Naïve-CQ & $0 / 5(0)$ & $0 / 5(0)$ & - \\
\hline Naïve-MQ & $0 / 5(0)$ & $0 / 5(0)$ & - \\
\hline Naïve & $0 / 5(0)$ & $0 / 5(0)$ & $0 / 5(0)$ \\
\hline
\end{tabular}

CPS-CQ immunization of $\mathrm{C} 57 \mathrm{BL} / 6 \mathrm{j}$ mice requires relatively high and lengthy drug prophylaxis to prevent development of $P$. berghei infection (K. NganouMakamdop, unpublished data). As a result, CPS-CQ mice cumulatively receive much more $C Q$ than the two doses of $800 \mu \mathrm{g}$ chloroquine diphosphate salt that were previously shown to improve cross-presentation [21]. Therefore, the effect of this low CQ-dose regimen on RAS immunization was assessed in a separate experiment, but protection levels were not higher than compared to RAS alone, indicating that the choice of CQ dose was not crucial.

Immune modulating effects of MQ have been reported but do not include cross-presentation [33,25-27]. It cannot be formally excluded that MQ in CPS immunization regimes may have similar properties as CQ. Both CQ and MQ are lysosomotropic agents that limit endosomal acidification [22], which for CQ is known to result in inhibition of lysosomal enzymes that require an acidic $\mathrm{pH}$ to function and the fusion of endosomes with lysosomes [34]. As such CQ, but not MQ, has been widely used to study the role of endosomal acidification in cellular processes [35]. CQ has also been studied extensively for its inhibitory effect on autophagy [17], but a recent publication suggests that MQ has similar effects on autophagy [36]. Because both endosomal acidification and autophagy might influence antigen presentation, the effect of MQ on these processes may result in immune modulating effects just as is the case for CQ.

In the absence of evidence for a direct immunemodulating effect of $\mathrm{CQ}$ during whole sporozoite immunization, it cannot be ruled out that both CQ and MQ might instead contribute to the efficient induction of protection in an indirect way. A review of rodent sporozoite immunization studies demonstrates the importance of optimal exposure to the entire repertoire of liver stage antigens as occurs during CPS-CQ and CPSMQ, with reduced protective efficacy if liver stage development is halted by drugs or in the case of RAS or genetically attenuated parasites [37]. Furthermore, some reports show a negative effect of blood-stage parasites on induced pre-erythrocytic $\mathrm{CD}^{+} \mathrm{T}$ cell responses by interfering with dendritic cell function [38,1]. By limiting exposure to blood stages during CPS immunization, CQ and MQ might thus have an indirect positive effect on pre-erythrocytic immunity.

\section{Conclusions}

This study does not provide evidence of improved immune responses or protective efficacy by CQ in the $P$. berghei model. Instead, the higher efficiency of CPS compared to RAS in humans might be explained by an indirect effect of CQ through limiting blood-stage exposure after immunization or to an improved breadth of the immune response as a result of increased antigen exposure. In the absence of a clear immune enhancing effect of CQ here, more work is needed to assess whether these findings can be translated to human settings.

\section{Additional file}

Additional file 1: Study designs. The effect of chloroquine (CQ) on immune responses and protection by whole sporozoite immunization was tested in a number of $P$. berghei models. Balb/cByJ (A) and $\mathrm{C} 57 \mathrm{BL} / 6 \mathrm{j}$ mice (B) received intravenous (iv) immunizations with radiation attenuated sporozoites (RAS; immunization dose in grey), with or without additional administration of CQ (grey bars). All mice were challenged by iv injection of $10 \times 10^{3}$ wild type (WT) P. berghei sporozoites (spz), and followed up with blood smears for the detection of parasites. (C) C57BL/ 6j mice were immunized with $P$. berghei $C S^{5 M}$ RAS after receiving CD45.1 + OT-1 cells, with or without CQ prophylaxis (grey bar). Expansion of CD45. $1^{+} \mathrm{CD}^{+}$SIINFEKL cells in liver and spleen was assessed by flow cytometry 10 days after immunization. (D) C57BL/6j mice were immunized by iv administration of WT $P$. berghei spz while receiving either $C Q$ or mefloquine (MQ) prophylaxis, then challenged after 50 days with either $10 \times 10^{3}$ or $50 \times 10^{3}$ WT berghei spz or after 100 days with $10 \times 10^{3} \mathrm{WT}$ berghei spz, and followed up with blood smears for the detection of parasites.

\section{Abbreviations}

CQ: Chloroquine; CPS: Chemoprophylaxis and Sporozoites; CS protein: Circumsporozoite protein; HMC: Hepatic mononuclear cell; MQ: Mefloquine; PbiRBC: $P$. berghei infected red blood cells;

PBMC: Peripheral blood mononuclear cell; PbSPZ: P. berghei sporozoites; RAS: Radiation attenuated sporozoite; Tem: Cells with effector memory phenotype. 


\section{Competing interests}

The authors declare that they have no competing interests.

\section{Authors' contributions}

EB, KN, IC, FZ and RS conceived the experiments; EM, KNM, GVG and IC carried out the experiments and analysed the data. EM, KNM and RS drafted the manuscript. All authors read and approved the manuscript.

\section{Acknowledgments}

We would like to thank Alex Inacio, Mike Peters, Iris Lamers-Elemans, Claudia Lagarde, Debby Smits and Nynke Tichelaar for technical assistance with the mice experiments and Jolanda Klaassen, Laura Pelser-Posthumus, Astrid Pouwelsen and Jacqueline Kuhnen for breeding the mosquitoes. EMB was supported by Top Institute Pharma (grant T4-102) and KN was supported by the NWO Mozaiek (grant no. 017.005.011).

\section{Author details}

${ }^{1}$ Department of Medical Microbiology, Radboud University Medical Center, P.O. Box 9101, 6500 HB Nijmegen, The Netherlands. ${ }^{2} J o h n s$ Hopkins Malaria Research Institute and Department of Molecular Microbiology and Immunology, John Hopkins Bloomberg School of Public Health, Johns Hopkins University, Baltimore, MD 21205, USA. ${ }^{3}$ Current address: Vaccine Research Centre; National Institutes of Health, 40 Convent drive, Bethesda, MD 20892, USA. ${ }^{4}$ Current address: John Curtin School of Medical Research, Australian National University, GPO Box 334, Canberra City ACT 2600, Australia.

\section{Received: 24 December 2014 Accepted: 20 February 2015} Published online: 26 March 2015

\section{References}

1. Orjih AU. Acute malaria prolongs susceptibility of mice to Plasmodium berghei sporozoite infection. Clin Exp Immunol. 1985;61:67-71.

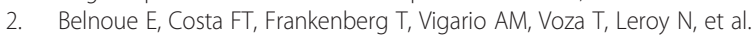
Protective $T$ cell immunity against malaria liver stage after vaccination with live sporozoites under chloroquine treatment. J Immunol. 2004;172:2487-95.

3. Nussenzweig RS, Vanderberg J, Most H, Orton C. Protective immunity produced by the injection of $\mathrm{x}$-irradiated sporozoites of Plasmodium berghei. Nature. 1967;216:160-2.

4. Roestenberg M, McCall M, Hopman J, Wiersma J, Luty AJ, van Gemert GJ, et al. Protection against a malaria challenge by sporozoite inoculation. N Engl J Med. 2009;361:468-77.

5. Bijker EM, Teirlinck AC, Schats R, van Gemert G-J, van de Vegte-Bolmer M, van Lieshout $L$, et al. Cytotoxic markers associate with protection against malaria in human volunteers immunized with Plasmodium falciparum sporozoites. J Infect Dis. 2014;210:1605-15.

6. Hoffman SL, Goh LM, Luke TC, Schneider I, Le TP, Doolan DL, et al. Protection of humans against malaria by immunization with radiation-attenuated Plasmodium falciparum sporozoites. J Infect Dis. 2002;185:1155-64.

7. Nganou-Makamdop K, van Gemert GJ, Arens T, Hermsen CC, Sauerwein RW. Long term protection after immunization with P. berghei sporozoites correlates with sustained IFNgamma responses of hepatic CD8+ memory T cells. PLoS One. 2012;7:e36508.

8. Teirlinck AC, McCall MBB, Roestenberg M, Scholzen A, Woestenenk R, de Mast $\mathrm{Q}$, et al. Longevity and composition of cellular immune responses following experimental Plasmodium falciparum malaria infection in humans. PLoS Pathog. 2011;7:e1002389. doi: 10.1371/journal.ppat.

9. Berenzon D, Schwenk RJ, Letellier L, Guebre-Xabier M, Williams J, Krzych U. Protracted protection to Plasmodium berghei malaria is linked to functionally and phenotypically heterogeneous liver memory CD8+ T cells. J Immunol. 2003;171:2024-34

10. Guebre-Xabier M, Schwenk R, Krzych U. Memory phenotype CD8(+) T cells persist in livers of mice protected against malaria by immunization with attenuated Plasmodium berghei sporozoites. Eur J Immunol. 1999;29:3978-86.

11. Jobe O, Lumsden J, Mueller AK, Williams J, Silva-Rivera H, Kappe SH, et al. Genetically attenuated Plasmodium berghei liver stages induce sterile protracted protection that is mediated by major histocompatibility complex Class I-dependent interferon-gamma-producing CD8+ T cells. J Infect Dis. 2007;196:599-607.

12. Jobe O, Donofrio G, Sun G, Liepinsh D, Schwenk R, Krzych U. Immunization with radiation-attenuated Plasmodium berghei sporozoites induces liver
cCD8alpha + DC that activate CD8 + T cells against liver-stage malaria. PLoS One. 2009;4:e5075

13. Sedegah M, Weiss WW, Hoffman SL. Cross-protection between attenuated Plasmodium berghei and P. yoelii sporozoites. Parasite Immunol. 2007;29:559-65.

14. Inoue M, Tang J, Miyakoda M, Kaneko O, Yui K, Culleton R. The species specificity of immunity generated by live whole organism immunisation with erythrocytic and pre-erythrocytic stages of rodent malaria parasites and implications for vaccine development. Int J Parasitol. 2012;42:859-70.

15. Cockburn IA, Tse SW, Radtke AJ, Srinivasan P, Chen YC, Sinnis P, et al. Dendritic cells and hepatocytes use distinct pathways to process protective antigen from Plasmodium in vivo. PLoS Pathog. 2011;7:e1001318.

16. Wellems TE, Plowe CV. Chloroquine-resistant malaria. J Infect Dis. 2001;184:770-6.

17. Solomon VR, Lee H. Chloroquine and its analogs: a new promise of an old drug for effective and safe cancer therapies. Eur J Pharmacol. 2009;625:220-33.

18. Vincent MJ, Bergeron E, Benjannet S, Erickson BR, Rollin PE, Ksiazek TG, et al. Chloroquine is a potent inhibitor of SARS coronavirus infection and spread. Virol J. 2005;2:69.

19. Accapezzato D, Visco V, Francavilla V, Molette C, Donato T, Paroli M, et al. Chloroquine enhances human CD8+ T cell responses against soluble antigens in vivo. J Exp Med. 2005;202:817-28.

20. Garulli B, Di Mario G, Sciaraffia E, Accapezzato D, Barnaba V, Castrucci MR. Enhancement of T cell-mediated immune responses to whole inactivated influenza virus by chloroquine treatment in vivo. Vaccine. 2013:31:1717-24.

21. Garulli B, Stillitano MG, Barnaba V, Castrucci MR. Primary CD8+ T-cell response to soluble ovalbumin is improved by chloroquine treatment in vivo. Clin Vaccine Immunol. 2008;15:1497-504.

22. Ginsburg H. Antimalarial drugs: is the lysosomotropic hypothesis still valid? Parasitol Today. 1990;6:334-7.

23. Brossart $P$, Bevan MJ. Presentation of exogenous protein antigens on major histocompatibility complex class I molecules by dendritic cells: pathway of presentation and regulation by cytokines. Blood. 1997;90:1594-9.

24. Romero P, Maryanski JL, Corradin G, Nussenzweig RS, Nussenzweig V, Zavala F. Cloned cytotoxic T cells recognize an epitope in the circumsporozoite protein and protect against malaria. Nature. 1989;341:323-6.

25. Bygbjerg IC, Svenson M, Theander TG, Bendtzen K. Effect of antimalarial drugs on stimulation and interleukin 2 production of human lymphocytes. Int J Immunopharmacol. 1987;9:513-9.

26. Bygbjerg IC, Theander TG, Andersen BJ, Flachs $H$, Jepsen S, Larsen PB. In vitro effect of chloroquine, mefloquine and quinine on human lymphocyte proliferative responses to malaria antigens and other antigens/mitogens. Trop Med Parasitol. 1986;37:245-7.

27. Pedersen BK, Bygbjerg IC, Theander TG, Andersen BJ. Effects of chloroquine, mefloquine and quinine on natural killer cell activity in vitro. An analysis of the inhibitory mechanism. Allergy. 1986;41:537-42.

28. Matuschewski K. Murine infection models for vaccine development: the malaria example. Hum Vaccin Immunother. 2013;9:450-6.

29. Watarai H, Nakagawa R, Omori-Miyake M, Dashtsoodol N, Taniguchi M. Methods for detection, isolation and culture of mouse and human invariant NKT cells. Nat Protoc. 2008:3:70-8.

30. Sun P, Schwenk R, White K, Stoute JA, Cohen J, Ballou WR, et al. Protective immunity induced with malaria vaccine, RTS, S, is linked to Plasmodium falciparum circumsporozoite protein-specific CD4+ and CD8+ T cells producing IFN-gamma. J Immunol. 2003;171:6961-7.

31. Bongfen SE, Torgler R, Romero JF, Renia L, Corradin G. Plasmodium berghei-infected primary hepatocytes process and present the circumsporozoite protein to specific CD8+ T cells in vitro. J Immunol. 2007; 178:7054-63.

32. Shakushiro K, Yamasaki Y, Nishikawa M, Takakura Y. Efficient scavenger receptor-mediated uptake and cross-presentation of negatively charged soluble antigens by dendritic cells. Immunology. 2004;112(2):211-8.

33. Labro MT, Babin-Chevaye C. Effects of amodiaquine, chloroquine, and mefloquine on human polymorphonuclear neutrophil function in vitro. Antimicrob Agents Chemother. 1988;32:1124-30.

34. Schlesinger $\mathrm{PH}$, Krogstad DJ, Herwaldt BL. Antimalarial agents: mechanisms of action. Antimicrob Agents Chemother. 1988;32:793-8.

35. Mellman I, Fuchs R, Helenius A. Acidification of the endocytic and exocytic pathways. Annu Rev Biochem. 1986;55:663-700. 
36. Sharma N, Thomas S, Golden EB, Hofman FM, Chen TC, Petasis NA, et al. Inhibition of autophagy and induction of breast cancer cell death by mefloquine, an antimalarial agent. Cancer Lett. 2012;326:143-54.

37. Nganou-Makamdop K, Sauerwein RW. Liver or blood-stage arrest during malaria sporozoite immunization: the later the better? Trends Parasitol. 2013:29:304-10.

38. Ocana-Morgner C, Mota MM, Rodriguez A. Malaria blood stage suppression of liver stage immunity by dendritic cells. J Exp Med. 2003;197:143-51.

Submit your next manuscript to BioMed Central and take full advantage of:

- Convenient online submission

- Thorough peer review

- No space constraints or color figure charges

- Immediate publication on acceptance

- Inclusion in PubMed, CAS, Scopus and Google Scholar

- Research which is freely available for redistribution 